\title{
New Heterogeneous Metal-Oxides Based Catalyst for Vegetable Oil Trans-esterification
}

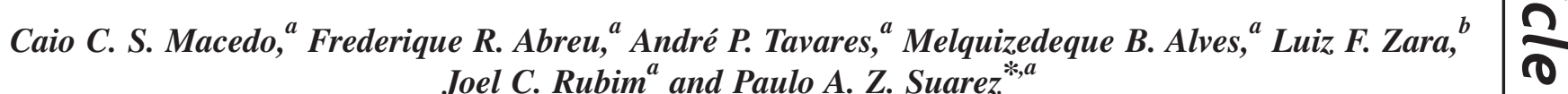 \\ ${ }^{a}$ Instituto de Química, Universidade de Brasília, CP 4478, 70919-970 Brasilia-DF, Brazil \\ ${ }^{b}$ Universidade Católica de Brasília, Brasília-DF, Brazil
}

\begin{abstract}
Neste trabalho são apresentados a preparação de novos materiais obtidos da co-precipitação de alumina e óxidos de estanho e zinco e seu uso como sistemas catalíticos ativos para alcoólise de óleos vegetais. Foi observado que estes óxidos metálicos do tipo $\left(\mathrm{Al}_{2} \mathrm{O}_{3}\right)_{\mathrm{X}}(\mathrm{SnO})_{\mathrm{Y}}(\mathrm{ZnO})_{\mathrm{Z}}$ são ativos para a alcoólise do óleo de soja usando diversos álcoois, incluindo ramificados. Os melhores resultados foram observados utilizando metanol, sendo atingidas conversões acima de $80 \% \mathrm{em}$ 4 horas. Foi também possível reciclar estes materiais sem perda aparente de sua atividade catalítica.
\end{abstract}

The preparation of new materials obtained from the co-precipitation of aluminum, tin and zinc oxides and their use as catalytic system activities for vegetable oils alcoholysis are reported herein. It was observed that these metal-oxides of the type $\left(\mathrm{Al}_{2} \mathrm{O}_{3}\right)_{\mathrm{X}}(\mathrm{SnO})_{\mathrm{Y}}(\mathrm{ZnO})_{\mathrm{Z}}$ are active for soybean oil alcoholysis, uzing several alcohols, including branched ones. Best result was achieved using methanol, with conversion yields up to $80 \%$ in $4 \mathrm{~h}$. It was also possible to recycle the catalysts without apparent loss of activity.

Keywords: trans-esterification, biodiesel, vegetable oils, heterogeneous catalyst

\section{Introduction}

The catalytic trans-esterification of vegetable oils with methanol is an important industrial method used in biodiesel synthesis. ${ }^{1,2}$ Also known as methanolysis, this reaction is well studied and established using acids or alkalis, such as sulfuric acid or sodium hydroxide as catalysts. ${ }^{3,4}$ However, these catalytic systems are less active or completely inactive for long chain alcohols. ${ }^{5}$ Usually, industries use sodium or potassium hydroxide or sodium or potassium methoxide as catalyst, since they are relatively cheap and quite active for this reaction. Unfortunately, the use of alkaline hydroxides or carbonates tends to produce water and soap in the system, ${ }^{6}$ generating emulsions, which end up compromising the final purification step. ${ }^{7}$

Different attempts have been made in order to develop alternative ways to minimize these problems. For instance, a few studies have been carried out under non-catalytic conditions..$^{8-11}$ However, in many of these studies, the reactor surface metals were actually responsible for the

* e-mail: psuarez@unb.br catalysis. ${ }^{8}$ Furthermore, the use of heterogeneous catalytic systems has also been proposed alcoholysis of triglycerides. ${ }^{12-16}$ For example, Schuchardt et al. ${ }^{12}$ studied the alcoholysis of vegetable oil in the presence of alkylguanidines supported on an organic polymer. Despite the fact that this system showed interesting reaction yields (up to $95 \%$ ) at $70{ }^{\circ} \mathrm{C}$, the amine leaching and its irreversible protonation caused rapid deactivation of the catalytic system, making its recycling difficult. Leclercq et al. ${ }^{13}$ proposed the use of cesium-exchanged $\mathrm{NaX}$ faujasites and commercial hydrotalcite (KW2200) as catalysts. It was observed that in the presence of cesium exchanged $\mathrm{NaX}$ faujasites using a high methanol/vegetable oil ratio ( $c a$. 275) and $22 \mathrm{~h}$ under reflux, the alcoholysis achieved conversion yields of up to $70 \%$, where as $34 \%$ yield was obtained in the presence of hydrotalcite under the same conditions. Bayense et al. ${ }^{14}$ patented the use of titanium and titanium aluminum zeolites. Using the commercial available ETS-4 and ETS-10 zeolites as catalysts the authors claimed to have achieved conversions of up to $85 \%$ and $52 \%$, respectively, after $90 \mathrm{~min}$, at $220{ }^{\circ} \mathrm{C}$. Using calcium carbonate rock as catalyst, Suppes et al. ${ }^{15}$ achieved after 18 min residence time conversions of up to $78 \%$ and $95 \%$ 
at 240 and $260{ }^{\circ} \mathrm{C}$, respectively, for the ethanolysis of soybean oil. It is interesting to highlight that, except for the study carried out by Schuchardt et al.,${ }^{12}$ temperatures above $200{ }^{\circ} \mathrm{C}$ were required in order to achieve conversion yields higher than $90 \%$.

We showed ${ }^{16}$ that tin oxide was active for soybean oil methanolysis in a heterogeneous system achieving reaction yields of up to $93 \%$ in $3 \mathrm{~h}$ at $60{ }^{\circ} \mathrm{C}$. It is interesting to note that we were able to recover and reuse the catalyst three times without any loss of catalytic activity.

Recently it was shown that doping alumina with $\mathrm{NaOH}$ and sodium affords a basic solid that was active for the transesterification of vegetable oils. Indeed, optimizing the reaction conditions it was possible to achieve reaction yields using the $\mathrm{Na} / \mathrm{NaOH} / \gamma$-alumina heterogeneous base catalyst comparable to those obtained using $\mathrm{NaOH}$ in homogeneous conditions. ${ }^{17} \mathrm{We}$ report herein the preparation of metal-oxides of the type $\left(\mathrm{Al}_{2} \mathrm{O}_{3}\right)_{\mathrm{X}}(\mathrm{SnO})_{\mathrm{Y}}(\mathrm{ZnO})_{\mathrm{Z}}$ together with their behavior as heterogeneous catalysts in the trans-esterification reaction of soybean oil with different alkyl-chain alcohols.

\section{Experimental}

\section{Reagents}

Reagent grade tin(II) chloride, zinc(II) sulfate, aluminum nitrate, sodium carbonate and sodium hydroxide were obtained from commercial sources (Aldrich, Milwaukee, WI) and were used as received without further purification. Refined soybean oil was obtained from commercial sources (Bunge, Gaspar - Santa Catarina State, Brazil) and used as received. Methanol $(\mathrm{MeOH})$, ethanol (EtOH), $n$-propanol ( $n$-PropOH), iso-propanol ( $i$-PropOH), n-butanol ( $n$-ButOH), tert-butanol $(t$-ButOH), and cyclohexanol $(c-\mathrm{HexOH})$ were analytical grade, obtained commercially (Merck), and used as received.

\section{Preparation of the catalysts}

Different solids were prepared using a co-precipitation method adapted from the literature. ${ }^{18}$

Preparation of $\left(\mathrm{Al}_{2} \mathrm{O}_{3}\right)_{4}(\mathrm{SnO})(\mathbf{1})$. A $100 \mathrm{~mL}$ water solution containing hydrated tin(II) chloride $(1.128 \mathrm{~g}, 5 \mathrm{mmol})$ and $50 \mathrm{~mL}$ of an aqueous solution of hydrated aluminum nitrate (7.502 g, $20 \mathrm{mmol}$ ) were slowly added under magnetic stirring to a $100 \mathrm{~mL}$ aqueous solution of sodium carbonate ( $9.3 \mathrm{~g}$ of $\mathrm{NaCO}_{3}$ in $100 \mathrm{~mL}$ of $\mathrm{H}_{2} \mathrm{O}$ ). The mixture was left stirring at room temperature for $30 \mathrm{~min}$ and then kept in a refrigerator overnight. The resulting precipitates were isolated by filtration, washed several times with distilled water, and dried in a vacuum desiccator over silica gel. The precipitates were then thermally activated at $500{ }^{\circ} \mathrm{C}$ for $4 \mathrm{~h}$, yielding $1.380 \mathrm{~g}$ of $\left(\mathrm{Al}_{2} \mathrm{O}_{3}\right)_{8}(\mathrm{SnO})_{2}$.

Preparation of $\left(\mathrm{Al}_{2} \mathrm{O}_{3}\right)_{4}(\mathrm{ZnO})$ (2). $4.10 \mathrm{~g}$ of solid 2 was prepared using hydrated zinc sulfate $(1.437 \mathrm{~g}, 5 \mathrm{mmol})$ and hydrated aluminum nitrate $(7.502 \mathrm{~g}, 20 \mathrm{mmol})$ following a similar procedure as described for $\mathbf{1}$.

Preparation of $\left.\mathrm{Al}_{2} \mathrm{O}_{3}\right)(3)$. A water solution of hydrated aluminum nitrate (7.502 g, $20 \mathrm{mmol})$ was slowly added under magnetic stirring to an aqueous solution of sodium carbonate $\left(9.3 \mathrm{~g}\right.$ of $\mathrm{Na}_{2} \mathrm{CO}_{3}$ in $100 \mathrm{~mL}$ of $\mathrm{H}_{2} \mathrm{O}$ ). The mixture was left stirring for $30 \mathrm{~min}$ at room temperature and then kept in a refrigerator overnight. The resulting precipitates were isolated by filtration, washed several times with distilled water, and dried in a vacuum desiccator over silica gel. The washed precipitates were thermally activated at $500{ }^{\circ} \mathrm{C}$ for $4 \mathrm{~h}$, affording $1.786 \mathrm{~g}$ of solid $\mathbf{3}$.

\section{Characterization of the catalysts}

ICP emission spectroscopy. The amounts of tin, zinc and aluminum present in the catalysts were determined using a Varian Liberty RL Series II Inductively Coupled PlasmaOptical Emission Spectrometer (ICP OES).

Surface area $(B E T)$. The surface areas of the catalysts were obtained by the BET method using the "Micromeritics" analyzer model ASAP-2010. The isotherms were obtained through adsorption of $\mathrm{N}_{2}$ at $77.30 \mathrm{~K}$.

Determination of the acidity. The catalysts' surface acidities were determined by the Hammett's indicators method $^{19,20}$ using bromothymol blue, methyl yellow and crystal violet under nitrogen atmosphere. Three indicator solutions were prepared by dissolving each indicator $(0.2$ $\mathrm{mg})$ in freshly distilled carbon tetrachloride $(100 \mathrm{~mL})$. Under nitrogen atmosphere, solids $\mathbf{1}, \mathbf{2}$ and $\mathbf{3}(0.1 \mathrm{~g})$ were each mixed with a different indicator solution $(5 \mathrm{~mL})$ resulting in a total of nine different mixtures. These mixtures were then titrated using a $0.05 \mathrm{~mol} \mathrm{~L}^{-1}$ solution of $n$-butyl amine dissolved in carbon tetrachloride.

Spectral data. The infrared spectra (DRIFT - Diffuse Reflectance Infrared Fourier Transform) were obtained from the powder samples on a Bruker Equinox 55 interferometer. The Raman spectra of the powder samples 
were obtained with the same instrument using a Raman accessory, and the signal collected in backscattering geometry was detected by a liquid nitrogen, cooled $\mathrm{Ge}$ detector. Each Raman spectrum is the average of 128 scans at $8 \mathrm{~cm}^{-1}$ spectral resolution. The FT-IR spectra were stored in the Kubelka-Munk mode and are the average of 32 scans at a nominal spectral resolution of $4 \mathrm{~cm}^{-1}$.

Catalytic experiments. The vegetable oil (10 g) was transesterified in the presence of different alkyl-chain alcohols ( $1.5 \mathrm{~g}$ ) using $0.5 \mathrm{~g}$ of solids $\mathbf{1}, \mathbf{2}$ or $\mathbf{3}$ as catalysts. The reaction mixtures were kept in a $50 \mathrm{~mL}$ batch reactor under gentle reflux (at approximately $60{ }^{\circ} \mathrm{C}$ ) and magnetic stirring for the desired time. The product obtained was washed three times with distilled water. The recovered esters were analyzed using gas chromatography on a Shimadzu GC-17A chromatograph with FID detector, equipped with a polydimethylsiloxane column (CBPI PONA-M50-042, 50 $\mathrm{m}, 0.25 \mathrm{~mm}$ i.d. and film thickness of $0.2 \mu \mathrm{m}$ ), at temperatures that varied from 80 to $180{ }^{\circ} \mathrm{C}$, with a heating rate of $10{ }^{\circ} \mathrm{C}$ $\mathrm{min}^{-1}$. Ethyl acetate $(0.1 \mathrm{~g})$ was added to the washed product and used as internal standard. The conversion yields were then calculated comparing the mass of recovered mono-ester and the initial mass of soybean oil.

\section{Results and Discussion}

\section{Chemical analysis}

Solids $\mathbf{1}$ and $\mathbf{2}$ were prepared using the co-precipitation method. ${ }^{18}$ By ICP OES analysis, it was verified that the amounts of tin, zinc and aluminum present in the catalysts were in excellent agreement with the calculated composition (see Table 1).

Table 1. Chemical analysis obtained for the ICP OES of catalysts 1 $\left[\left(\mathrm{Al}_{2} \mathrm{O}_{3}\right)_{4}(\mathrm{SnO})\right]$ and $2\left[\left(\mathrm{Al}_{2} \mathrm{O}_{3}\right)_{4}(\mathrm{ZnO})\right]$

\begin{tabular}{lcccc}
\hline Catalyst composition & $\mathrm{Al}_{2} \mathrm{O}_{3} /(\boldsymbol{\%})$ & $\mathrm{SnO} /(\boldsymbol{\%})$ & $\mathrm{ZnO} /(\boldsymbol{\%})$ \\
\hline $\mathbf{1}$ & calculated & 80.0 & 20.0 & \\
& found & 81.3 & 18.7 & - \\
$\mathbf{2}$ & calculated & 80.0 & & 20.0 \\
& found & 80.0 & - & 20.0 \\
\hline
\end{tabular}

\section{BET surface area}

The surface area of solids $\mathbf{1}\left(12 \mathrm{~m}^{2} \mathrm{~g}^{-1}\right), \mathbf{2}\left(82 \mathrm{~m}^{2} \mathrm{~g}^{-1}\right)$ and $3\left(142 \mathrm{~m}^{2} \mathrm{~g}^{-1}\right)$ were determined by the BET method. It is interesting to note that the surface area increases when zinc is used instead of tin. The BET surface area obtained for solid $\mathbf{3}$ is in agreement with the value usually obtained for commercial alumina, approximately $150 \mathrm{~m}^{2} \mathrm{~g}^{-1}$.
Determination of the acidity

The Hammett indicator method provided $\mathrm{H}_{\mathrm{o}}$ values for the solids $\mathbf{1}, \mathbf{2}$, and $\mathbf{3}$ which all lie between 4 and 6 . The surface acidity order obtained for this solids is $\mathbf{3}>\mathbf{1}>\mathbf{2}$.

\section{$I R$ and Raman analysis}

The infrared spectra of $\mathrm{Al}_{2} \mathrm{O}_{3}$ and $\mathrm{Al}_{2} \mathrm{O}_{3}$-based products usually show three well-defined absorptions in the spectral region corresponding to the $\mathrm{OH}$ stretching mode, $v(\mathrm{OH}){ }^{21-24}$ Table 2 shows the characteristic $\mathrm{v}(\mathrm{OH})$ infrared absorptions reported for alumina samples $\left(\alpha-\right.$ and $\gamma-\mathrm{Al}_{2} \mathrm{O}_{3}$ ) as well as the corresponding absorptions observed in the infrared spectra of solids $\mathbf{1}$ and $\mathbf{3}$.

Table 2. Main absorptions (in $\mathrm{cm}^{-1}$ ) observed in the $\mathrm{v}(\mathrm{OH})$ spectral region of the infrared spectra of alumina-based samples

\begin{tabular}{lccc}
\hline$\alpha-\mathrm{Al}_{2} \mathrm{O}_{3}[20-23]$ & $\gamma-\mathrm{Al}_{2} \mathrm{O}_{3}[20-23]$ & $\mathbf{1}$ & $\mathbf{3}$ \\
\hline 3798 & 3732 & $3656(\mathrm{sh}) *$ & $3656(\mathrm{sh}) *$ \\
3740 & 3699 & 3620 & 3620 \\
3677 & 3549 & 3525 & 3525 \\
\hline
\end{tabular}

$*$ sh $=$ shoulder

The absorption at higher wavenumbers (3798 or 3732 $\mathrm{cm}^{-1}$ ) is assigned to terminal hydroxyl groups while the intermediary mode ( 3740 or $3699 \mathrm{~cm}^{-1}$ ) is due to the bridged $\mathrm{OH}$ groups shared by an octahedrally and a tetrahedrally coordinated aluminum cation. The bands observed for wavenumbers bellow $3600 \mathrm{~cm}^{-1}$ are attributed to the $\mathrm{OH}$ groups in different surface sites..$^{24}$ These modes are very sensitive to the local geometry and to the presence of other ions incorporated in the lattice.

Note that the wavenumbers corresponding to the absorptions for solids $\mathbf{1}$ and $\mathbf{3}$ are closer to the absorptions of the $\gamma-\mathrm{Al}_{2} \mathrm{O}_{3}$ but are shifted to lower wavenumbers. It should also be noted that although solid $\mathbf{1}$ contains $c a$. $20 \% \mathrm{SnO}$ the $\mathrm{v}(\mathrm{OH})$ absorptions are observed at the same wavenumbers as for solid $\mathbf{3}$. These results suggest that the presence of $\mathrm{SnO}$ does not causes any change in the $\mathrm{OH}$ groups associated to the alumina.

The DRIFT spectra of the investigated catalysts are displayed in Figure 1. In contrast to catalysts $\mathbf{1}$ and $\mathbf{3}$, the spectrum of catalyst $\mathbf{2}$, which presents $20 \%$ of $\mathrm{ZnO}$, does not show the fine structures observed in the $v(\mathrm{OH})$ region. This observation suggests that the presence of $\mathrm{ZnO}$ in the catalyst modifies the $\mathrm{OH}$ bonding modes in the alumina surface.

It is well known that alumina also presents an absorption band at $c a .1620 \mathrm{~cm}^{-1}$ and a broad feature below $900 \mathrm{~cm}^{-1} .{ }^{25}$ The DRIFT spectrum of solid 3 shows well- 
defined absorption bands at $c a .1640,1511,1390,1069$, and $1023 \mathrm{~cm}^{-1}$. The band at $1640 \mathrm{~cm}^{-1}$ is typical of the $\mathrm{OH}$ bending mode, $\delta(\mathrm{OH})$, due to water absorbed on the solid surface. The other absorptions are due to the presence of carbonate in the sample, as discussed later.

Catalysts 1 and 2 contain significant amounts of $\mathrm{SnO}$ or $\mathrm{ZnO}$. A comparison of the DRIFT spectra of catalysts 1 and 2 with those of $\mathrm{SnO}$ and $\mathrm{ZnO}$, shows that none of the bands observed in Figure 1 can be due to the presence of pure $\mathrm{SnO}$ and $\mathrm{ZnO}$ in the samples, respectively.
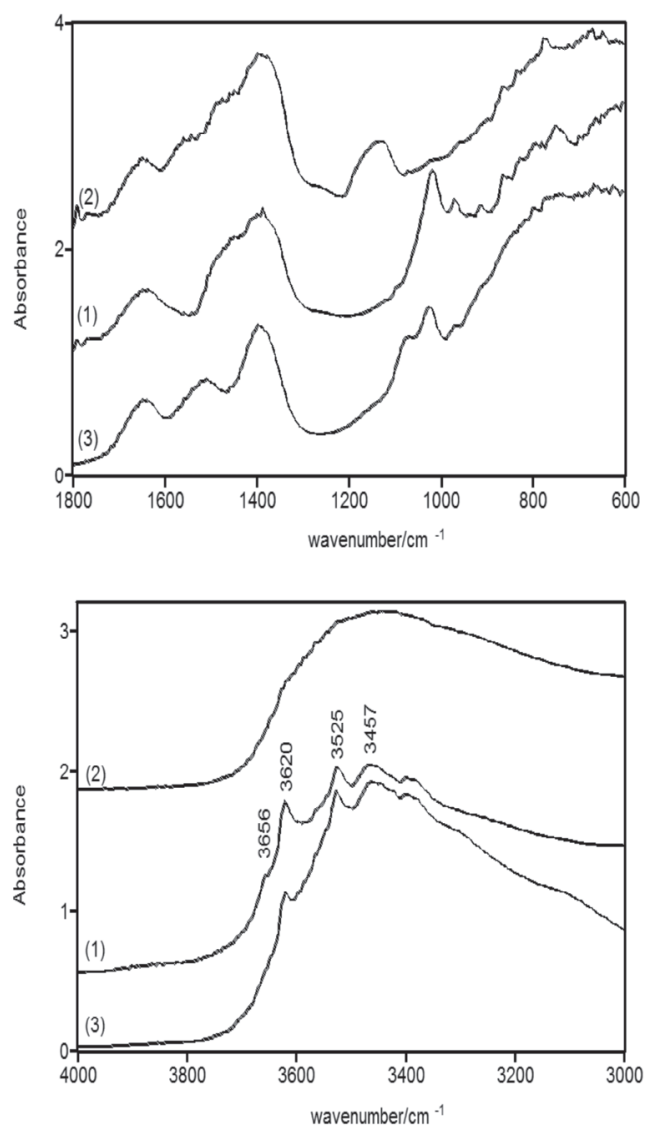

Figure 1. DRIFT spectra of $(\mathbf{1})\left(\mathrm{Al}_{2} \mathrm{O}_{3}\right)_{4}(\mathrm{SnO}),(2)\left(\mathrm{Al}_{2} \mathrm{O}_{3}\right)_{4}(\mathrm{ZnO})$ and (3) $\mathrm{Al}_{2} \mathrm{O}_{3}$.

Unfortunately no direct specific reference in the literature concerning the FTIR spectrum of pure $\mathrm{SnO}$ was found. The only reference found was related to the study of doped $\mathrm{SnO} / \mathrm{Na}_{3} \mathrm{PO}_{4}$ glasses. ${ }^{26}$ Samples containing $45 \% \mathrm{SnO}$ and $55 \% \mathrm{Na}_{3} \mathrm{PO}_{4}$ exhibited some bands at $c a$. 544, 978, and $1190 \mathrm{~cm}^{-1}$, which where not observed in the DRIFT spectrum of solid 2. It is worth mentioning that no absorption band was observed for these $\mathrm{SnO}$ doped glasses in the spectral region between 1200 and $1700 \mathrm{~cm}^{-1}$

The FT-Raman spectra of catalysts $\mathbf{1}, \mathbf{2}$ and $\mathbf{3}$ and of $\mathrm{Na}_{2} \mathrm{CO}_{3}$ are displayed in Figure 2. As reported in the literature, the FT-Raman spectra of alumina shows signals with reasonable intensities only for temperatures ranging from 1050 to $1250{ }^{\circ} \mathrm{C}^{27}$ At room temperature the spectrum consists of only an intense background in the region between 100 and $2000 \mathrm{~cm}^{-1}$ with no defined feature. The FT-Raman spectrum of solid $\mathbf{3}$ presents only a weak feature at $c a .1050 \mathrm{~cm}^{-1}$. All original spectra of the investigated catalysts have an intense background as mentioned above. This background was corrected in order to compare the FT-Raman spectra.

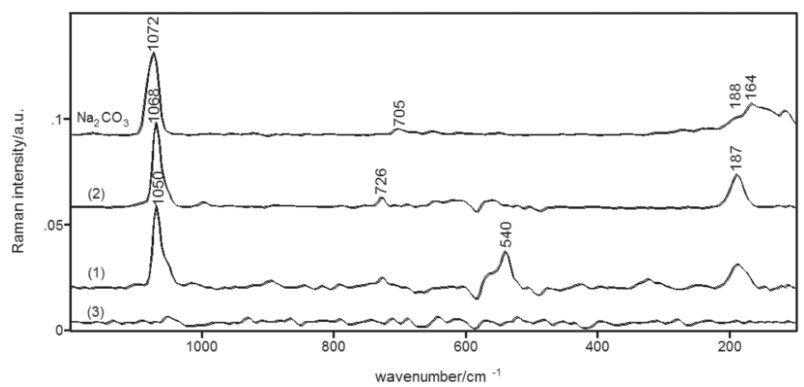

Figure 2. Raman spectra of (1) $\left(\mathrm{Al}_{2} \mathrm{O}_{3}\right)_{4}(\mathrm{SnO}),(\mathbf{2})\left(\mathrm{Al}_{2} \mathrm{O}_{3}\right)_{4}(\mathrm{ZnO})_{1},(\mathbf{3})$ $\mathrm{Al}_{2} \mathrm{O}_{3}$ and $\mathrm{Na}_{2} \mathrm{CO}_{3}$. The spectra were baseline corrected to reduce the intense background signal.

The Raman spectrum of pure $\mathrm{SnO}$ presents bands at 113,211 , and $260 \mathrm{~cm}^{-1} .{ }^{28}$ According to quantum mechanics calculations another Raman transition is expected to be seen between 460 and $490 \mathrm{~cm}^{-1} .^{29}$ None of these bands were observed in solids $\mathbf{1}$ and $\mathbf{2}$. The Raman feature observed at $c a .540 \mathrm{~cm}^{-1}$ may be related to the presence of $\mathrm{SnO}$ in the sample.

The Raman spectrum of pure $\mathrm{ZnO}$ shows several bands which include $331,383,410,438,540,584,660,776$, 987,1101 , and $1154 \mathrm{~cm}^{-1}$. The most intense band can be seen at $438 \mathrm{~cm}^{-1} \cdot{ }^{30}$ As it is shown in Figure 2, no feature near $438 \mathrm{~cm}^{-1}$ is observed in the FT-Raman spectrum of solid 2.

For comparison purposes, the FT-Raman spectrum of pure sodium carbonate is also displayed in Figure 2. This spectrum shows signals at $164,188,705$, and $1072 \mathrm{~cm}^{-1}$. Note that all catalysts have a feature near $1050-1070 \mathrm{~cm}^{-1}$. Further, solids 1 and 2 do also present a feature near $180 \mathrm{~cm}^{-1}$. The results obtained in this section together with those obtained in the FTIR analysis suggest that carbonate is present in the investigated samples, which is reasonable since they were prepared by precipitation in a sodium carbonate solution.

\section{Soybean oil trans-esterification}

We studied the catalytic performance of solids $\mathbf{1}, \mathbf{2}$ and $\mathbf{3}$ for soybean methanolysis and the main results can be seen in Figure 3. These results show that the reaction yields are almost independent of the relative amounts of tin and zinc present in catalysts $\mathbf{1}$ and $\mathbf{2}$. Indeed, all 
catalytic systems achieve conversion yields of about $80 \%$ after $4 \mathrm{~h}$ at $60{ }^{\circ} \mathrm{C}$. At the end of reaction, the catalysts were recovered, washed with methanol and dried at $100{ }^{\circ} \mathrm{C}$ for $1 \mathrm{~h}$. They were then reused three times under the same conditions, reaching similar yields (see Figure 4).

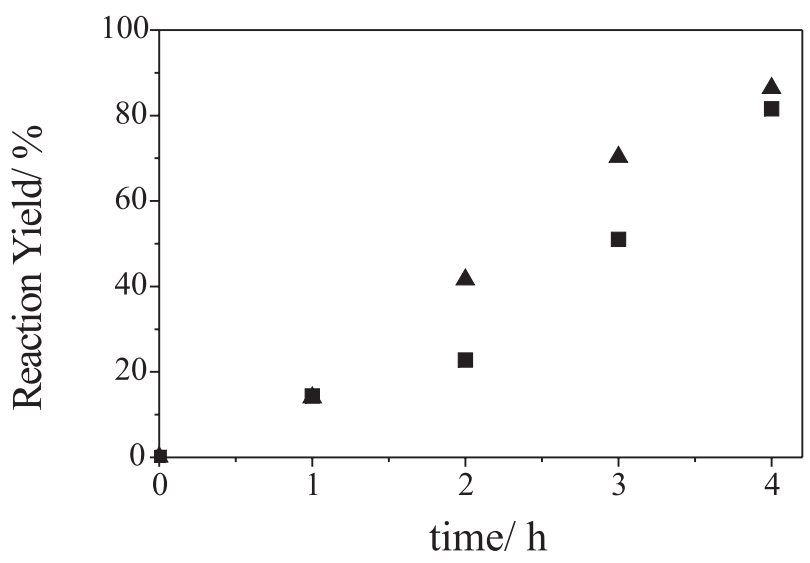

Figure 3. Methylesther production in soybean oil transesterification in the presence of solids $\mathbf{1}(\mathbf{\square})$ and $\mathbf{2}(\mathbf{\Lambda})$.

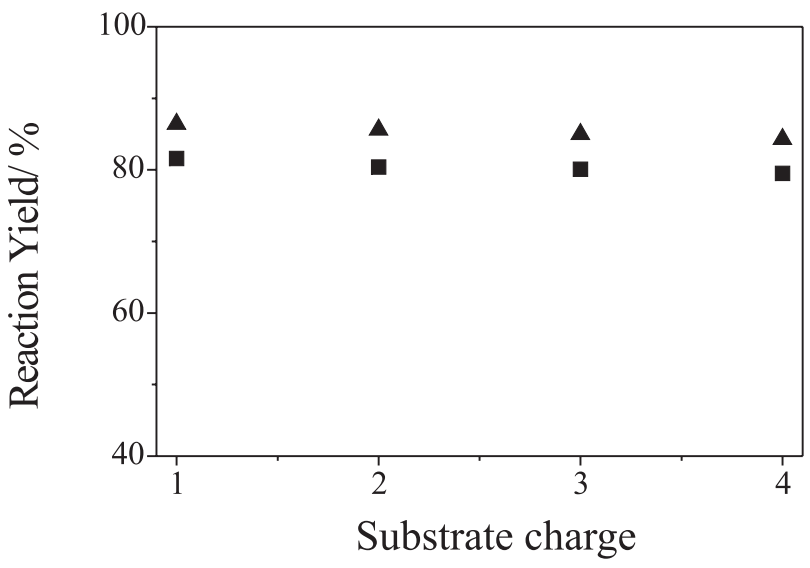

Figure 4. Reaction yields observed for four charges of soybean oil using solids $1(\boldsymbol{\square})$ and $\mathbf{2}(\boldsymbol{\Lambda})$ : fresh solid (charge 1) and recovered solids (charges 2-4).

Solids $\mathbf{1}$ and $\mathbf{2}$ showed similar catalytic activities for soybean methanolysis. Solid 2 was chosen to be used in the study of alcoholysis using other alcohols. Table 4 summarizes the main results obtained for the alcoholysis of soybean oil using different alkyl-chain alcohols under similar reaction conditions. As observed in Table 3 , the catalytic activities are strongly dependent on the nature of the alcohol. For alcohols with a linear chain, the reaction activities decrease with increasing chain length (for example, compare entries 1, 2, 3 and 5 of Table 4). It is worth mentioning that the activity decreases drastically in all reaction systems when branched alcohols are used (for example, compare entries 4 and 6 of Table 4). These results strongly suggest that steric effects control these catalytic activities.
Using the same preparation method that was used for the solids, pure alumina (solid $\mathbf{3}$, where $\mathrm{Y}=\mathrm{Z}=0$ ) was obtained. The methanolysis of soybean oil carried out in the presence of solid $\mathbf{3}$ achieved a conversion yield of $30 \%$ after $4 \mathrm{~h}$ using the same experimental conditions as used when solids $\mathbf{1}$ and $\mathbf{2}$ were tested.

Table 3. Alcoholysis of Soybean oil using catalyst 2 with different alcohols with the same alcohol/vegetable oil/catalyst mass ratio (1.5:10:0.5)

\begin{tabular}{lcc}
\hline Entry & Alcohol & Yield / (\%) $)^{\mathrm{a}}$ \\
\hline 1 & $\mathrm{MeOH}$ & 84.3 \\
2 & EtOH & 28.30 \\
3 & $n$-PropOH & 1.60 \\
4 & $i$-PropOH & 0.20 \\
5 & $n$-ButOH & 0.07 \\
6 & $t$-ButOH & 0.20 \\
7 & $c$-HexOH & 4.00 \\
\hline
\end{tabular}

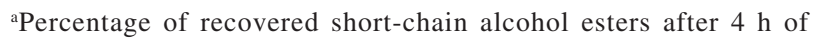
transesterification per initial mass of vegetable oil.

\section{Conclusions}

In summary, it was shown that metal-oxides of the type $\left(\mathrm{Al}_{2} \mathrm{O}_{3}\right)_{4}(\mathrm{SnO})$ and $\left(\mathrm{Al}_{2} \mathrm{O}_{3}\right)_{4}(\mathrm{ZnO})$ are indeed active for the transesterification reaction of soybean oil with different alkyl-chain alcohols. Few differences were observed for the reaction yield of soybean methanolysis assisted by solids $\mathbf{1}$ or $\mathbf{2}$. This is probably due to the fact that the solids possessed similar surface structures, independently of the presence oj tin or zinc in their composition. It was also shown that the highest catalytic activities are achieved with the use of short and linear chain alcohols.

\section{Acknowledgments}

Financial supports by FAPDF, FINATEC, DPP-UnB, FINEP-CTENERG and FINEP-CTPETRO are gratefully acknowledged. C. C. M., M. B. A., A. P. T., F. R. A., J.C.R. and P.A.Z.S. express their appreciation for fellowships granted by PIBIC-CNPq, PET-MEC and CNPq.

\section{References}

1. Zhang, Y.; Dubé, M. A.; McLean, D. D.; Kates, M.; Bioresour. Technol. 2003, 89, 1.

2. Farris, R. D.; J. Am. Oil Chem. Soc. 1979, 56, 770.

3. Freedman, B.; Butterfield, R. O.; Pryde, E. H.; J. Am. Oil Chem. Soc. 1986, 63, 1375.

4. Vicente, G.; Martinez, M.; Aracil, J.; Bioresour. Technol. 2004, 92, 297.

5. Stern, R.; Hillion, G.; Rouxel, J. J.; Leporq, S.; U.S. pat. 5,908,946, 1999. 
6. Filip, V.; Zajic, V.; Smidrkal, J.; Revue Français des Corps Gras 1992, 39, 91.

7. Mittelbach, M.; Tritthart, P.; J. Am. Oil Chem. Soc. 1988, 65, 1185.

8. Dasari, M. A.; Goff, M. J.; Suppes, G. J.; J. Am. Oil Chem. Soc. 2003, 80, 189.

9. Kusdiana, D.; Saka, S.; Fuel 2001, 80, 693.

10. Saka, S.; Kusdiana, D.; Fuel 2001, 80, 225.

11. Diasakou, M.; Louloudi, M.; Papayannakos, N.; Fuel 1998, 77, 1297.

12. Schuchardt, U.; Vargas, R. M.; Gelbard, G.; J. Mol. Catal. A: Chem. 1996, 109, 37.

13. Leclercq, E.; Finiels, A.; Moreau, C.; J. Am. Oil Chem. Soc. 2001, 78, 1161.

14. Bayense, C. R.; Hinnekens, H.; Martens, J.; US pat 5,508,457 1996.

15. Suppes, G. J.; Bockwinkel, K.; Lucas, S.; Botts, J. B.; Mason, M. H.; Heppert, A. J.; J. Am. Oil Chem. Soc. 2001, 78, 139.

16. Abreu, F. R.; Alves, M. B.; Macêdo, C. C. S.; Zara, L. F.; Suarez, P. A. Z.; J. Mol. Catal. A: Chem. 2005, 207, 263.

17. Kim, H.-J.; Kang, B.-S. ; Kim, M.-J. ; Park, Y. M.; Kim, D.-K.; Lee, J.-S.; Lee, K.-Y.; Catal. Today 2004, 93-95, 315.

18. Marion, M. C.; Garbowski, E.; Primet, M.; J. Chem. Soc. Faraday Trans. 1991, 87, 1795.
19. Hammett, L. P.; Deyrup, A. J.; J. Am. Chem. Soc., 1932, 54, 2721.

20. Kijenski, J.; Baiker, A.; Catal. Today 1989, 5, 1.

21. Peri, J. B.; Hannan, R. B.; J. Phys. Chem. 1960, 64, 1526.

22. Peri, J. B.; J. Phys. Chem. 1965, 69, 211.

23. Harkness, I. R.; Lambert, R. M.; J. Catal. 1995, 152, 384.

24. Heracleous, E.; Lemonidou, A. A.; Lercher, J. A.; Appl. Catal., A 2004, 264, 73.

25. Tsuchida, T.; Solid State Ionics 1993, 63, 464.

26. Bhat, M. H.; Berry, F. J.; Jiang, J. Z.; Rao, K. J.; J. Non-Cryst. Solids 2001, 291, 93.

27. Aminzadeh, A.; Sarikhani-fard, H.; Spectrochim. Acta, Part A 1999, 55, 1421.

28. Geurts, J.; Rau, S.; Richter, W.; Schmitte, F. J.; Thin Solid Films 1984, 121, 217.

29. Koval, S.; Burriel, R.; Stachiotti, M. G.; Castro, M.;. Migoni, R. L.; Moreno, M. S.; Varela, A.; Rodriguez, C. O.; Phys. Rev. B: Condens. Matter Mater. Phys. 1999, 60, 14496.

30. Wang, R. P.; Xu, G.; Jin, P.; Phys. Rev. B: Condens. Matter Mater. Phys. 2004, 69, 113303.

Received: September 12, 2005 Published on the web: August 30, 2006 